\title{
Iran Talks: Das Palavras aos Atos. A Declaração de Teerã e o Plano de Ação Conjunto de Genebra em Perspectiva*
}

Antonio Jorge Ramalho da Rocha** e Pérola Mourão de Souza Sardo de Abreu Pereira***

\section{Introdução}

No dia 24 de novembro de 2013, o Irã e o grupo negociador P5+1 ${ }^{1}$ chegaram a um acordo, em Genebra, acerca do programa nuclear iraniano. Trata-se de um acordo provisório, mas também de um evento histórico, que merece exame detido.

As razões por que o Irã optou pelo acordo são controversas. Tampouco há consenso acerca da medida em que as sanções internacionais impostas pelo Conselho de Segurança das Nações Unidas (CSNU) influenciaram a decisão iraniana em Genebra. O certo é que nenhu-

\footnotetext{
* Artigo recebido em 7 de março de 2014 e aprovado para publicação em 27 de agosto de 2014.

** Doutor em Ciências Sociais pela Universidade de São Paulo (USP) e professor do Instituto de Relações Internacionais da Universidade de Brasília (iREL-UnB). E-mail: antonio.ramalho@ gmail.com.

*** Mestra em Relações Internacionais pela Universidade de Brasília (UnB) e pesquisadora do Instituto Pandiá Calógeras do Ministério da Defesa. E-mail: perolabreu@gmail.com.
}

CONTEXTO INTERNACIONAL Rio de Janeiro, vol. 36, nº 2, julho/dezembro 2014, p. 655-682. 
ma interpretação estará inteiramente isenta de juízo de valor. Isso é relevante porque, neste caso, as interpretações não são neutras: se forem bem construídas, poderão contribuir para plasmar percepções e, por conseguinte, atitudes - da comunidade internacional com respeito ao compromisso iraniano de implementar o acordo firmado. Ao afetar a opinião prevalecente na mídia ocidental, por exemplo, tais interpretações também poderão impactar, indiretamente, as ações da comunidade internacional.

A relevância do assunto dispensa comentários extensos. Pelo menos desde fins dos anos 1970, as tensões criadas em torno do Irã e de seu programa nuclear nas últimas décadas, justificadas ou não, ocuparam analistas e operadores de política externa em caráter permanente. Mesmo países cujas relações com a nação persa são distantes, positivas ou simplesmente incontroversas sempre tiveram presente o fato de que as repercussões de um conflito envolvendo o Irã lhes atingiriam os interesses precípuos de forma contundente, donde a preocupação em acompanhar os acontecimentos na região.

No caso dos Estados Unidos, por razões históricas, a relação com o Irã constitui sensível prioridade nos campos da defesa e da política externa, estendendo-se a seus aliados. Evidências disso não faltam. Em recente discurso voltado para reafirmar a parceria entre os EUA e os países europeus, o atual secretário de Defesa realçou a importância do Irã, ao lado de suas preocupações com Rússia e China, ao mesmo tempo em que expôs a perspectiva que interessa aos EUA:

Um desenvolvimento de postura importante é a defesa europeia em resposta às ameaças de mísseis balísticos do Irã. Ao longo dos dois últimos dias, eu estive na Polônia, onde reafirmei o compromisso dos Estados Unidos de implantar lá uma arquitetura de defesa antimíssil. Como vocês todos sabem, isso é parte da terceira fase da nossa abordagem europeia, adaptativa e gradual (HAGEL, 2014). 
Voos de imaginação são desnecessários para imaginar as repercussões de semelhante discurso em Teerã. A mensagem de desconfiança é clara e reafirma uma posição que, no Irã, é percebida como parte de um conjunto de pressões destinadas a isolar o país, privando-o de desenvolver tecnologias que lhe são necessárias para atender aos anseios de sua população, em termos quer de acesso aos empregos pacíficos da tecnologia nuclear, quer de prestígio no plano internacional.

Não por acaso, o atual presidente iraniano busca convencer a opinião pública internacional da necessidade de se deixar no passado as tensões herdadas de sessenta anos de intervenções externas nos assuntos domésticos de seu país e do caráter pacífico de seu programa nuclear. ${ }^{2}$ Entre as alegações, ganha relevo a fatwa proclamada pelo líder supremo, aiatolá Ali Khamenei, que reafirma a crença de que "o desenvolvimento, a produção, a estocagem e o uso de armas nucleares são contrários às normas islâmicas" (ROUHANI, 2014). Por essa razão, continua Rouhani (2014), "nós nunca contemplamos a opção de adquirir armas nucleares, porque nós acreditamos que essas armas poderiam comprometer nossos interesses de segurança nacional". 3

Outro aspecto a ser observado é a reação ao acordo por parte dos chamados "linha dura", isto é, os grupos mais conservadores no espectro político iraniano. A sociedade iraniana caracteriza-se por enorme complexidade, e seu sistema político está longe de ser monolítico, não obstante a influência dos aiatolás. A opacidade que marca as dinâmicas políticas daquele país não favorece precisar o grau de apoio da parcela mais conservadora da sociedade iraniana ao Acordo de Genebra. Isso também é relevante, pois, a depender do apoio desses grupos, percepções ocidentais enviesadas sobre as intenções de Teerã eventualmente encontrarão respaldo, influenciando negativamente os governos do P5+1 no que concerne à sua disposição de engajar o Irã em negociações mais profundas sobre a normalização de suas relações com o resto do mundo. 
Nesse contexto, comparar o Acordo de Genebra com os termos da Declaração de Teerã, firmada por Irã, Brasil e Turquia há pouco mais de três anos, permite jogar luz sobre o significado histórico das duas iniciativas. Embora formulados para atender ao mesmo objetivo, os dois acordos diferem em vários aspectos. Pelo menos três merecem atenção especial: o método de negociação e os atores envolvidos; a amplitude; e a essência formal dos acordos firmados.

Essas diferenças não explicam o injustificável contraste entre os destinos de cada processo negociador. Mas seu exame permite levantar hipóteses acerca das razões pelas quais as grandes potências, havendo rejeitado a Declaração de Teerã, mostram-se otimistas com relação ao Acordo de Genebra.

Este artigo compara esses acordos e registra lições que se pode tirar dos erros e acertos associados a cada um deles, visando contribuir para estabelecer expectativas realistas acerca da implementação do Acordo de Genebra e de suas implicações para as relações internacionais nos próximos anos. O texto organiza-se em três seções: a primeira explica o pano de fundo em que se desenvolveram os acordos e descreve seus respectivos objetivos; a segunda examina os processos negociadores que marcaram sua condução; e a terceira avalia os aspectos positivos e negativos de cada um deles, em perspectiva comparada. Segue-se breve conclusão.

\section{Do Pano de Fundo e dos Objetivos dos Acordos}

Os dois acordos tratam dos limites do programa nuclear iraniano e objetivam contribuir para a consolidação da paz, especialmente no Oriente Médio. Buscam, também, comprometer o Irã com medidas que demonstrem a intenção pacífica de seu programa nuclear - um 
instrumento para construir confiança em suas relações com a comunidade internacional, notadamente com os Estados Unidos.

Nenhum deles afirma isso abertamente, mas o pano de fundo das negociações sobre a questão nuclear é geopolítico. Caso o Irã obtenha armas nucleares, a região observará profundo rearranjo na distribuição relativa de poder entre as principais potências. No momento em que os EUA reduzem sua presença no Oriente Médio e na Ásia, isso não interessa à maioria dos países dessas regiões - menos ainda à Arábia Saudita.

O que ficou conhecido como "a questão nuclear iraniana" expressa o temor de que o país se nuclearize, contribuindo para desestabilizar ainda mais uma região que sofre com numerosas tensões: o histórico e persistente conflito israelo-palestino; Israel nuclearmente armado; a milenar rivalidade entre sunitas e xiitas; a questão curda; e instabilidades internas que afetam as realidades domésticas e regionais - de que são exemplos as marchas e contramarchas da Primavera Árabe. Mais recentemente, os riscos de fragmentação política no Iraque e a crise na Síria adicionaram complexidade à equação.

Em outras palavras, é difícil prever quais seriam as implicações da posse de armas nucleares pelo Irã na dinâmica de poder do Oriente Médio. Sua interpretação reclama considerações de ordem geopolítica, uma vez que, para citar os exemplos mais óbvios, a Arábia Saudita pode sentir-se constrangida a perseguir o mesmo objetivo; e Israel a assumir sua condição de potência nuclear. Reclama também análise das nuances que contribuem para fazer do Irã um Estado marginalizado por parte da comunidade internacional e o inimigo preferido da maioria dos países do Oriente Médio.

De fato, embora o Irã seja signatário do Tratado de Não Proliferação Nuclear (TNP) e tenha direito a desenvolver um programa nuclear pacífico, conforme estabelece o TNP em seu artigo $4^{\stackrel{0}{ }}$, parte da comunidade internacional sistematicamente desacredita nas alegações 
iranianas de que seu programa nuclear tenha natureza pacífica. O discurso agressivo do ex-presidente Ahmadinejad, o viés tradicionalmente adotado na mídia ocidental e a impressão de que o Irã resiste ao monitoramento internacional de seu programa nuclear decerto contribuíram para fortalecer a percepção dessa parte da comunidade internacional de um Irã que, mal-intencionado, constituiria séria ameaça à paz e à segurança internacionais.

A Agência Internacional de Energia Atômica (AIEA) monitora o Irã ininterruptamente desde 2003. ${ }^{4}$ A presença constante de inspetores da AIEA no país contradiz a suposição de que o Irã resistiu sistematicamente a esse monitoramento. Entretanto, é fato que, a partir de certo momento, seu governo deixou de comunicar à Agência novos desenvolvimentos em seu programa nuclear. Além disso, sua resistência a implementar o disposto em resoluções do Conselho de Segurança da ONU (em especial a 1.696 e a 1.737, ambas de 2006) alimentou a construção da imagem do Irã como Estado-ameaça.

Sobejamente explorada por grupos conservadores nos Estados Unidos e em Israel, principalmente ao longo da última década, essa imagem contribuiu para isolar o Irã. Mesmo parcialmente desprovida de fundamento em fatos, essa percepção é forte o suficiente para mobilizar recursos e influenciar as políticas externas das grandes potências.

Como resultado, a identidade iraniana, tal como percebida no Ocidente, aproxima o país persa da posição de inimigo - o que também serve a interesses políticos internos, particularmente em tempos de campanha eleitoral. Isso contrasta fortemente, por exemplo, com o caso de Israel. Com efeito, embora não tenha assinado o TNP e sabidamente possua artefato nuclear não declarado oficialmente, o país está longe de ser usualmente percebido como ameaça no Ocidente. ${ }^{5}$

Refém dessa imagem e inserido na peculiar dinâmica política do Oriente Médio, o Irã é alvo de desconfianças de países como Israel e Arábia Saudita, que, embora por razões distintas, temem sua maior 
projeção. A aliança entre o Irã, grupos como o Hamas e países como a Síria reforça o paradigma da oposição ao Irã. Além disso, o medo do chamado "crescente xiita" nitas (BARZEGAR, 2008), consubstanciadas no Conselho de Cooperação do Golfo (CCG) e lideradas pela Arábia Saudita, onde organizam tentativas de conter o Irã. Historicamente aliados aos EUA, esses países atuam habilmente junto à opinião pública e ao Congresso estadunidense, onde encontram solo fértil para reforçar a imagem ameaçadora do Irã, afastando o governo estadunidense de uma solução negociada com Teerã.

Ironicamente, contudo, nenhum país se beneficiou mais da política externa implementada pelos Estados Unidos na região nas últimas décadas do que o Irã, a despeito das hostilidades entre os dois países alimentadas seguidamente pelos dois Estados, vale dizer, não obstante as mudanças de governo que observaram. Ao assumirem o poder, os aiatolás tinham dois grandes inimigos no campo externo e um enorme desafio no plano doméstico. Os inimigos eram o Iraque, com quem o Irã travou sangrenta guerra ao longo dos anos 1980, e os talibãs. Graças aos EUA, o Iraque hoje está aberto à influência iraniana como seguramente não esteve no último século e meio, e os talibãs estão acuados, lutando para sobreviver ao conflito no Afeganistão.

Graças aos EUA, também, o governo iraniano conta com a coesão política que uma ameaça externa, como poucos outros fenômenos, proporciona a um governo minoritário, além de poder atribuir as atuais dificuldades socioeconômicas à imposição das sanções internacionais.

Por sua vez, a questão do direito a um programa nuclear pacífico, outrora praticamente ignorada pela sociedade iraniana, hoje constitui consenso entre as lideranças políticas nacionais, como exemplificaram as duas mais recentes eleições presidenciais. 
Ao cabo, inclusive devido ao inegável crescimento de sua influência na Ásia e no Oriente Médio ao longo da última década, o Irã encontra poucos aliados no Oriente Médio e é identificado como ameaça tanto por Israel quanto pela maioria dos países árabes.

Eis o pano de fundo dos acordos, em poucas palavras. Passemos, agora, ao exame dos processos negociadores.

\section{O Processo Negociador da Questão Nuclear Iraniana: Uma Comparação entre Teerã e Genebra}

Firmado em 2010, o documento de Teerã ${ }^{7}$ é enxuto: enumera dez itens em texto com natureza declaratória e operativa. Em contraste, o Plano de Ação Conjunto de Genebra constitui um acordo mais extenso, com um preâmbulo e três seções programáticas que totalizam 24 itens.

A Declaração de Teerã marca a posição comum dos três signatários, oferecendo solução alternativa às sanções econômicas impostas ao Irã bilateralmente pelos Estados Unidos e pela União Europeia, assim como às sanções multilaterais aprovadas no âmbito do Conselho de Segurança da ONU. Já o Plano de Ação Conjunto ${ }^{8}$ acordado pelo P5+1 e pelo Irã consiste em documento de ambição mais restrita e de caráter mais operacional. Trata-se de um instrumento provisório, destinado a criar confiança entre as partes e a anteceder um acordo mais amplo.

A rigor, nem Teerã nem Genebra proporcionam solução definitiva para a querela sobre o programa nuclear iraniano: ambos visam, por assim dizer, pavimentar o caminho para um bom entendimento futuro em outros âmbitos. A Declaração de Teerã firmou-se como uma peça de um processo negociador maior, que também envolvia outros 
atores, como a AIEA e o Grupo de Viena. ${ }^{9}$ Segundo seus termos, o Irã notificaria sua concordância com o depósito de urânio fracamente enriquecido (LEU) ${ }^{10}$ na Turquia, por meio dos canais oficiais, em até sete dias a contar da Assinatura da Declaração, quando o Grupo de Viena possivelmente viria a manifestar sua concordância com a Declaração. Após o reconhecimento da Declaração de Teerã, o que se previa era que um novo acordo de procedimento fosse firmado entre o Irã e o Grupo de Viena.

Claramente, a intenção do Brasil e da Turquia foi a de contribuir para um processo mais amplo, em que importava criar confiança inicial, necessária à promoção de uma solução definitiva no futuro.

De sua parte, o acordo de Genebra também foi concebido como o primeiro passo de um processo mais amplo, destinado a construir uma solução de longo prazo para a questão nuclear iraniana. $\mathrm{O}$ acordo tem duração definida de seis meses, período durante o qual as partes se comprometeram a manter atitude construtiva para fazer prosseguir as negociações em clima de boa-fé.

Uma diferença fundamental entre os dois acordos reside no juízo que cada documento faz da legitimidade de programas nucleares pacíficos. Em seu primeiro item, a Declaração de Teerã reafirma o compromisso dos três países signatários com o TNP e o direito de os Estados-parte no Tratado, inclusive o Irã, desenvolverem pesquisa, produção e uso de energia nuclear e atividades de enriquecimento, para fins pacíficos. Em linha com o artigo $4^{\circ}$ do TNP, não cabe discriminação adicional à que o texto do Tratado prevê - a qual, aliás, países como o Brasil questionam reiteradamente.

O acordo do $\mathrm{P} 5+1$, por sua vez, recupera a posição estadunidense de que o Irã não teria o direito de enriquecer urânio. Essa posição foi evidenciada pelo secretário de Estado estadunidense, John Kerry, nos comentários que teceu a respeito do Plano de Ação logo após sua aprovação, no dia 24 de novembro: "Este primeiro passo não quer di- 
zer que o Irã tem direito ao enriquecimento" (KERRY, 2013). Curiosamente, o mesmo Kerry, quando senador, ao criticar a política externa do governo Bush com relação ao Irã, declarou que o argumento da "administração Bush de não enriquecimento era ridículo [...] porque ele parecia tão pouco razoável para as pessoas" e, referindo-se aos direitos do Irã em sua condição de signatário do TNP, afirmou: "[Aquilo] era diplomacia retórica. Era perda de energia. [...] [Aquilo] meio que endurecia o discurso, se você quer saber. Eles têm direito ao poder nuclear pacífico e ao enriquecimento com esse propósito" (KERRY apud DOMBEY, 2009).

É possível interpretar a mudança de opinião do secretário de Estado como um aceno aos conservadores estadunidenses - um esforço no sentido de reduzir sua oposição ao acordo de Genebra, que integraria o jogo político típico nessas circunstâncias. Mas também é certo que, tanto do ponto de vista legal quanto do ângulo dos princípios que regem as relações internacionais contemporâneas, entre os quais o de tratamento igualitário dos Estados soberanos pelo direito internacional público, não se pode negar ao Irã o direito de desenvolver seu programa nuclear nos termos definidos pelo artigo $4^{\circ}$ do TNP.

A questão da legitimidade das sanções econômicas é outra divergência entre os grupos signatários dos acordos de agora e de 2010. Para Brasil e Turquia, negociadores da Declaração de Teerã, as sanções econômicas são um instrumento problemático, que deve ser evitado a todo custo, por razões políticas e humanitárias. As políticas relacionam-se com a ineficácia de sanções, evidenciada, por exemplo, pela experiência cubana; as humanitárias explicam-se pelo fato de que sanções em geral impõem sofrimento e restrições desnecessárias à população civil dos países a elas submetidos. Brasil e Turquia reiteram em seus discursos oficiais, ainda, que o diálogo é a melhor estratégia para resolver discordâncias e contenciosos entre os países. Esses países partem da premissa de que é possível convencer outros governos pelo diálogo e pela criação de benefícios laterais, fruto de 
criativa interpretação dos problemas em negociação ou mesmo de ofertas de terceiros países, que funcionam como "brokers".

Já Estados Unidos e Europa tradicionalmente aplicam sanções econômicas e embargos, e seu peso econômico (comercial e financeiro) confere a esses instrumentos significativo impacto sobre os países sancionados e embargados. Sua presunção é a de que os governos dos países alvo de sanções só mudarão seu curso de ação política se estiverem convencidos de que os custos de preservar suas políticas originais são inaceitavelmente elevados. Em vez do diálogo e da persuasão estimulada por expectativas de ganhos no futuro, neste caso prevalece a ideia de que os agentes políticos são movidos fundamentalmente pelo medo e pelo interesse em evitar prejuízos no porvir.

Os acordos incorporam, assim, diferentes posturas diante das relações internacionais. Marcam-se, ademais, pela patente disparidade de poder entre seus respectivos empreendedores, que, em alguma medida, informam as diferenças de abordagem empregada nos métodos utilizados para tentar solucionar a questão.

O processo que culminou na assinatura da Declaração de Teerã começou com uma solicitação do Irã à AIEA para compra de combustível à base de urânio enriquecido a $20 \%$ para abastecer o reator de pesquisas de Teerã, que produz isótopos medicinais para diagnóstico e cura de câncer. $\mathrm{O}$ formato das pastilhas de urânio combustível não permite que se continue o processo de enriquecimento, de modo que o urânio adquirido pelo Irã para seu reator de pesquisa não poderia, nem mesmo se o Irã quisesse, ser adicionalmente enriquecido a níveis que se aproximassem dos $90 \%$ necessários para com ele se construir um artefato nuclear.

O Grupo de Viena enxergou na solicitação iraniana à AIEA uma oportunidade de transformar a possível compra em uma permuta, em 
que o Irã entregaria parte de seu estoque de LEU em troca do combustível enriquecido a 20\%. Pretendia-se transformar, assim, a compra a que o Irã tinha direito (com base no TNP) em um criativo escambo, por meio do qual o Grupo de Viena conseguiria reduzir o estoque de LEU iraniano.

A proposta do Grupo de Viena era a de que o Irã deveria enviar imediatamente ao exterior 1.200 quilos de LEU enriquecido a 20\%, em troca de 120 quilos de urânio combustível para seu reator. Ao Irã não interessavam, no entanto, as quantidades propostas pelo Grupo de Viena. Os 120 quilos de urânio combustível excediam a quantidade que o Irã havia solicitado à AIEA, e seriam, provavelmente, desperdiçados em alguma medida, já que o tempo de vida útil que restava ao reator de pesquisa de Teerã era menor do que a vida útil do combustível enriquecido - cuja posse implicaria, ademais, custos de manutenção, já que as pastilhas deveriam permanecer guardadas em local seguro e sob permanente supervisão da AIEA. Entretanto, à época estimava-se que o Irã teria um estoque de LEU não utilizado em seus reatores de água leve de aproximadamente 1.200 quilos, cujo valor de mercado corresponderia a cerca de 120 quilos de Urânio medianamente enriquecido. Eis porque o Grupo de Viena insistia nos 120 quilos de combustível, parte dos quais seria ociosa - e onerosa-para Teerã.

O Irã tampouco concordava, como demandava o Grupo de Viena, em depositar o LEU no exterior antes de receber as pastilhas de combustível - interessava-se, ao contrário, por uma troca simultânea, de modo que o LEU permanecesse em território iraniano até o momento em que o país fosse, de fato, receber as pastilhas. Além das quantidades, havia, portanto, que se equacionar os elementos "tempo" e "local" da troca.

Brasil e Turquia inseriram-se nesse processo negociador, ao qual se convencionou chamar de Iran Talks, em franca e permanente coor- 
denação com os países do Grupo de Viena, e em um contexto no qual as gestões do grupo não logravam, sozinhas, viabilizar o acordo.

A Declaração foi firmada a 17 de maio 2010, na esteira de um contínuo diálogo de Brasil e Turquia tanto com o Irã quanto com os países do Grupo de Viena, notadamente os Estados Unidos. O presidente Obama chegou a enviar uma carta ao presidente Lula, ${ }^{11}$ a 20 de abril de 2010. Nela, confirmava os termos do acordo desejado pelo Grupo de Viena e a importância de que o Irã cedesse em relação aos elementos quantidade, tempo e local acima mencionados e que aceitasse depositar os 1.200 quilos de LEU na Turquia, como "caução", até que a AIEA disponibilizasse o urânio combustível. Obama questionava a "boa-fé" do Irã, mas instava o Brasil a dialogar com o Irã acerca da possibilidade de aceitar o esquema do depósito "caução" de LEU na Turquia.

Menos de um mês depois, o Irã cedeu nos três aspectos considerados substanciais pelo Grupo de Viena: a quantidade, o local e o prazo relacionados ao depósito de LEU fora do Irã. Em seus itens 5 e 6, a Declaração de Teerã estabeleceu os termos segundo os quais o Irã concordava em depositar 1.200 quilos de LEU na Turquia imediatamente, em troca do combustível. Enquanto permanecesse na Turquia e até que a AIEA lhe entregasse o urânio enriquecido a 20\%, os 1.200 quilos de LEU permaneceriam propriedade do Irã. A Declaração formalizou, ainda, o compromisso unilateral iraniano de enviar carta à AIEA, no prazo de até sete dias, notificando sua concordância com os termos da Declaração de Teerã, ${ }^{12}$ sem sequer ter a certeza de que o Grupo de Viena ofereceria reciprocidade ao gesto. ${ }^{13}$

Quando se tem presente que os termos da Declaração eram os mesmos estabelecidos pelo Grupo de Viena e que o acordo se fazia com um governo percebido como de "linha dura", resta evidente que o resultado foi significativo. Não por acaso, o ex-diretor-geral da AIEA, o diplomata egípcio Mohamed ElBaradei (DUARTE, 2010), não es- 
condeu, à época, sua satisfação com a Declaração de Teerã e declarou que, caso o Grupo de Viena reagisse ao acordo impondo novas sanções, seria como se "não aceitassem um 'sim' como resposta".

Dois outros fatos autorizam a interpretação de que dificilmente o acordo sofreria restrições de outros grupos políticos iranianos, o que conferiria mais credibilidade ao compromisso então firmado por Teerã. O primeiro era o consenso de diplomatas e analistas envolvidos no processo de que todos os passos dados por Teerã eram conhecidos e previamente autorizados pelo líder supremo, o aiatolá Khamenei. Sem seu consentimento, de fato, nenhum governo iraniano seria capaz de firmar um acordo dessa magnitude e se manter no poder. $\mathrm{O}$ segundo era o de este "sim" vir de um governo considerado ameaçador, o verdadeiro bastião da resistência aos EUA. Comparadas ao grupo de sustentação de Ahmadinejad, as demais organizações políticas iranianas gozavam de reputação simpática ao Ocidente e à normalização das relações do Irã com a comunidade internacional.

No entanto, o que se seguiu à assinatura da Declaração foi a aprovação ${ }^{14}$ de um novo pacote de sanções contra o Irã, em uma clara mensagem de que o acordo articulado por Brasil e Turquia seria desperdiçado. Permanece sem explicação essa mudança de posição do Grupo de Viena, assim como a recusa estadunidense em acolher a Declaração de Teerã, firmada nos exatos termos que os Estados Unidos haviam proposto tão pouco tempo antes - o presidente Obama chamara, na carta ao presidente Lula, de "rejeição sem explicação confiável" a recusa do Irã em aceitar o depósito de LEU na Turquia, ressaltando que essa medida contribuiria para reforçar a confiança e reduzir tensões regionais.

Ao que tudo indica, já não se atribui importância a essa rejeição, visto que o Acordo de Genebra não prevê a retirada de sequer um grama de urânio enriquecido do Irã. O Acordo de Genebra propõe o ensaio de uma trégua, na qual Irã e países ocidentais abrem mão de práticas e 
atitudes que encaminhavam suas relações na direção do conflito. Vejamos suas características com mais detalhes.

O Irã comprometeu-se a diluir metade de seu estoque de urânio enriquecido a $20 \%$, para que a concentração se reduza a não mais do que $5 \%$. Comprometeu-se, também, a não enriquecer qualquer quantidade de urânio acima de $5 \%$ nos próximos seis meses ${ }^{15}$ e a apenas manter, sem aumentar, o nível das atividades das plantas de enriquecimento de Natanz, Fordow e Arak. Comprometeu-se, por fim, a não estabelecer novas plantas de enriquecimento, aceitando, assim, o congelamento temporário de seu programa de enriquecimento de urânio.

A contrapartida do Grupo de Viena, em termos de redução de sanções, materializa-se no descongelamento de ativos e no arrefecimento de restrições à participação iraniana no sistema financeiro internacional e nos fluxos de comércio exterior: os P5 e a Europa comprometeram-se a pausar os esforços para continuar limitando as vendas de petróleo do Irã e a suspender sanções sobre serviços de seguro e de transporte relacionados à exportação de petróleo iraniano. EUA e União Europeia suspenderam, ainda, sanções às exportações de petroquímicos, ouro e metais preciosos, assim como aos serviços a elas associados, e à indústria automobilística iraniana. Firmou-se o compromisso de não lançar novas sanções relacionadas ao programa nuclear iraniano, tanto no âmbito da ONU quanto unilateralmente, pelos Estados Unidos. Estabeleceu-se, finalmente, um canal financeiro para facilitar o comércio humanitário que atenda às necessidades domésticas do Irã.

No que concerne ao monitoramento internacional do programa nuclear iraniano, o Plano de Ação de Genebra vai além da Declaração de Teerã. Pelo documento de Teerã, o urânio enviado à Turquia poderia ter sua guarda monitorada pelo Irã e pela AIEA, mas o monito- 
ramento mais amplo das instalações no país persa dependeria de novo acordo, continuado o processo negociador.

Esse foi, saliente-se, o principal argumento utilizado em 2010 pelo Grupo de Viena para justificar sua recusa a considerar seriamente a Declaração de Teerã, além do fato de que o Irã teria enriquecido quantidades adicionais de urânio enquanto as negociações se desenvolviam - das quais a Declaração não tratava. Obviamente, o fato de essa alegação ser provavelmente verdadeira não poderia constituir empecilho para que se aceitasse o resultado de uma negociação cujos limites haviam sido anteriormente fixados pelo próprio Grupo de Viena. Aliás, a ideia era justamente criar confiança nessas negociações iniciais, a fim de encetar sucessivos processos negociadores sobre distintos aspectos do programa nuclear iraniano.

Pelo documento de Genebra, o Irã compromete-se a prover a AIEA, no prazo de três meses, de informações específicas, inclusive planos e descrições de plantas nucleares, além de permitir o acesso diário de inspetores da AIEA e inspeções não anunciadas nas plantas de Fordow e Natanz. Em relação à planta de Arak, acordou-se o envio de informações que possibilitarão mecanismos de salvaguarda.

Diferentemente de Teerã, uma concessão unilateral do Irã em um gesto para criar confiança, Genebra resultou de uma barganha condicional, por meio da qual o Grupo de Viena ofereceu o alívio de sanções em troca de limitações ao programa nuclear iraniano. Em que pesem as diferenças e semelhanças entre os dois acordos, a efemeridade do acordo de Teerã parece injustificável quando contrastada com o entusiasmo despertado pelo texto de Genebra. A rejeição da Declaração de Teerã pelo Grupo de Viena e o lançamento de novas sanções menos de um mês depois de sua assinatura ampliaram ainda mais o isolamento da economia iraniana, justamente quando se esperava iniciar um novo ciclo de diálogo, animado pelo acordo a que se chegara. 
Se não se pode encontrar grande disparidade entre os efeitos que cada acordo poderia proporcionar com vistas a aceder a seu objetivo comum, como, então, explicar o contraste entre a rejeição de Teerã e o acolhimento de Genebra? Por que os Estados Unidos teriam assumido postura evasiva com relação à Declaração de Teerã, se aquele país não só já havia proposto solução similar, como também formularia documento com a mesma vocação três anos mais tarde? Como explicar que Genebra sequer menciona Teerã como parte do processo de construção de confiança em relação ao programa nuclear iraniano? As características domésticas no Irã e nos Estados Unidos são relevantes para a comparação entre os dois acordos?

Essas questões orientam o exame das possíveis razões que motivaram reações tão diversas a esses acordos.

\section{Das Possíveis Razões das Distintas Trajetórias dos Acordos}

Irã e Estados Unidos, dois atores-chave em ambos os processos negociadores, viviam situações domésticas distintas durante os dois processos negociadores em tela. Em 2010, o governo de Mahmoud Ahmadinejad oferecia margem de manobra mais estreita à negociação com as potências ocidentais, em particular com os Estados Unidos, se comparado ao atual governo de Hassan Rouhani. Eleito em junho de 2013, Rouhani sinalizou sua intenção de dialogar com os Estados Unidos e com as potências ocidentais já em sua campanha eleitoral e a materializou em diversas iniciativas, notadamente a nomeação de Javad Zarif para o posto de chanceler. Zarif representara o Irã na ONU de 2002 a 2007 e goza de boa reputação junto a interlocutores ocidentais.

Destaque-se, no entanto, que, não obstante as distintas conjunturas domésticas vividas pelo Irã nesses dois momentos, o país logrou ne- 
gociar dois acordos. Tanto com Ahmadinejad quanto com Rouhani, o Irã sentou-se à mesa de negociação e mostrou disposição para dialogar e ceder em prol dos acordos, que foram, no entanto, recebidos de maneiras distintas. $\mathrm{O}$ acordo firmado por Ahmadinejad foi recebido com desconfiança pela comunidade internacional ${ }^{16}$ e por parcela da mídia brasileira. Agora, com Rouhani, o acordo foi geralmente bem recebido e é encarado pela comunidade internacional como um primeiro passo para a solução da questão nuclear iraniana.

Cabe considerar, todavia, que uma nova mudança de conjuntura interna em que grupos menos moderados voltem ao poder no Irã poderia resultar no fracasso da implementação do acordo de Genebra. Já o acordo de Teerã, por ter sido firmado por um governo mais radical, provavelmente teria aceitação mesmo junto a grupos mais moderados e, por envolver os conservadores, faz sentido supor que provavelmente seria mais viável do ponto de vista político.

Nos Estados Unidos, o governo Barack Obama conduziu de maneiras antagônicas cada um dos processos. Em seu primeiro mandato, apesar de a retórica que marcou o início da administração ter sido a da aproximação com o Irã e com o Oriente, em geral, Obama rejeitou a Declaração de Teerã e destacou aspectos negativos da atuação internacional iraniana, aproximando-se de Israel. Observa-se, nesse caso, o funcionamento das dinâmicas de pressão de forças conservadoras internas, bem como de interesses eleitorais, que geralmente têm maior influência sobre os chefes do Executivo em seus primeiros mandatos.

Já no segundo mandato de Obama, um acordo firmado em termos que dão sequência às negociações de 2010 foi arquitetado pelo Departamento de Estado, com o apoio do presidente, embora a aprovação pelo Congresso não seja unânime. Os Estados Unidos parecem estar mais dispostos a enfrentar a desaprovação israelense em relação a qualquer medida de arrefecimento de tensões com o Irã e bem 
mais dispostos a negociar com o novo governo moderado iraniano, liderados por um presidente que não mais se preocupa com sua reeleição.

As dinâmicas da política doméstica estadunidense têm significativa influência sobre os rumos que toma a política externa daquele país e, não raro, constituem obstáculos a compromissos firmados pelo Departamento de Estado. Atualmente, por exemplo, novas sanções contra o Irã aguardam votação no Congresso estadunidense. Propostas por um grupo de treze senadores republicanos e treze senadores democratas no dia 19 de dezembro, semanas depois de vir a público o Acordo de Genebra, as sanções se apresentam como "preventivas" e seriam aplicadas caso o Irã não cumpra com o acordado em Genebra no devido prazo de validade.

Por fim, mas igualmente importante, os esforços do governo Obama no sentido de reduzir a dependência dos EUA do petróleo oriundo do Oriente Médio abrem espaço para redefinir sua relação com países-chave naquela região. $\mathrm{O}$ acelerado incremento da produção de gás de xisto e a importante ampliação da compra de petróleo oriundo do Golfo da Guiné e de outras partes do Atlântico Sul explicam, em parte, a redefinição das relações dos EUA com seus antigos aliados no Oriente Médio.

No que diz respeito ao Irã, além de seu fortalecimento político na região e da maior abertura política de seu atual governo, cabe ter presente o fato de que as sanções produzem elevados custos sociais, impondo constrangimentos políticos ao regime. A discreta cooperação com os EUA no campo da inteligência, especialmente com relação ao combate aos talibãs e à estabilização do Iraque, contribui para avançar uma situação na qual o Irã recebe dos EUA o tratamento respeitoso que vinha almejando há décadas. A necessidade de seu envolvimento na crise síria para que se chegue a qualquer solução ne- 
gociada também conspira a favor da redefinição de seu lugar na região.

A Declaração de Teerã oferecia, ainda, o inusitado elemento representado por seu inédito rol de negociadores. Desde meados do século passado, as questões de paz e segurança internacional são tradicional e monopolisticamente tratadas pelo mesmo seleto grupo de países. Encabeçado pelos Estados Unidos, este grupo possui assento permanente no CSNU e, conforme o caso, agrega um ou outro país rico e bem armado. Muitas vezes, suas decisões e exigências associam-se a seus interesses específicos e a medidas autoritárias, uni ou plurilaterais, de uso da força. Perdeu-se, com a rejeição à Declaração de Teerã, a oportunidade de renovar esse grupo, contribuindo para tornar mais representativo, senão mais democrático, o tratamento das questões de paz e segurança internacional.

Tratava-se, por assim dizer, de um desafio ao consórcio que tradicionalmente administrava as questões mais relevantes da paz e da guerra no ambiente internacional. E um desafio que se impôs em um momento particularmente delicado do CSNU: o governo Obama se empenhara em reconstruir a relação com a ONU - bastante prejudicada na gestão Bush - e já havia tentado, em duas ocasiões, impor sanções ao Irã. Essas tentativas haviam sido abortadas em favor desse processo de melhoria das condições políticas no seio do CSNU. Em fins de 2010, foi possível construir, no Conselho, o consenso em prol da imposição das sanções, um processo complexo e delicado. Assim, um dos temores dos EUA era o de desperdiçar a oportunidade criada com o consenso do P-5 naquele momento, algo que poderia levar muito tempo para ocorrer de novo. Entretanto, como argumenta Parsi (2012), a corrida pelas sanções tornou-se também uma corrida contra a diplomacia. É possível que essa mesma percepção tenha levado o Irã a ceder, em busca de evitar a imposição de sanções.

À época da assinatura da Declaração de Teerã, não faltaram manifestações de apoio ao seu teor e conteúdo e às posições dos países envol- 
vidos. Roger Cohen (2010) considerou que a Declaração de Teerã havia sido desnecessária e autoritariamente descartada quando constituía uma proposta muito aproximada daquela feita pelos Estados Unidos ao Irã em 2009 e uma ótima oportunidade de levar os dois países à mesa de negociação. Cerca de um ano depois da Declaração de Teerã, a própria Anne-Marie Slaughter (2011), ex-diretora de planejamento político do Departamento de Estado, ao tempo em que considerou o episódio uma oportunidade perdida "de estabelecer o precedente de manter-se o urânio iraniano fora do Irã e de trabalhar a questão dentro de uma moldura cooperativa, ao invés de coercitiva", reafirmou sua convicção de que o objetivo do Irã ao firmar o acordo seria apenas o de "salvar a [sua] cara".

O fato é que se excluiu a Declaração de Teerã do processo de construção de confiança em relação ao programa nuclear iraniano. Ela não é sequer mencionada, seja nos documentos, seja nos diálogos que deram continuidade aos Iran Talks. Os Estados Unidos e os demais negociadores ocidentais parecem não ter encontrado condições para arcar com os custos da aproximação com o Irã, nem para reconhecer o Brasil e a Turquia como interlocutores de alto perfil nessa questão. $\mathrm{O}$ resultado foi a manutenção do rol tradicional de interlocutores da questão do programa nuclear iraniano. Postergou-se, ademais, por três anos, o passo inicial na direção de melhores relações do Irã com o Ocidente.

Ao longo desse período, o Irã enfrentou sanções que prejudicaram sua população e sua economia, mas também aumentou consideravelmente seus estoques de LEU e ampliou suas instalações nucleares. Ao que tudo indica, o emprego de sanções produziu o efeito oposto ao que se pretendia, a um custo humanitário elevado e desnecessário.

\section{Conclusões}

As negociações que levaram à Declaração de Teerã desenrolaram-se em condições políticas adversas, tanto no ambiente internacional, de 
forma mais ampla, quanto nos dois Estados-chave, EUA e Irã. O momento em que se viu a presença de emergentes se envolvendo diretamente em assuntos de paz e segurança internacional, na tentativa de destrinchar uma questão que se arrastava problemática havia anos, coincidiu com a viabilização da possibilidade de sanções no CSNU e com condições políticas específicas nos EUA. Nesse contexto, a Declaração de Teerã não vingou. Tratou-se de uma oportunidade perdida de se promover a normalização das relações do Irã com a comunidade internacional, que tinha a vantagem de reduzir a imagem ameaçadora do país ao retirar de seu território grande quantidade de urânio enriquecido.

No plano do discurso, o principal obstáculo ao acolhimento da Declaração de Teerã pelo Grupo de Viena foi a desconfiança de que o Irã tenha agido de má-fé, aproveitando-se dos esforços do Brasil e da Turquia. Essa justificativa encontra ressonância na imagem de um Irã mal-intencionado, que planeja construir um arsenal nuclear, que objetiva desequilibrar o status quo geopolítico do Oriente Médio e que desrespeita as recomendações do CSNU. No plano concreto, não havia obstáculos significativos à implementação do plano traçado em Teerã, a não ser o timing político inadequado à consecução dos objetivos que as grandes potências perseguiam no CSNU.

Embora a relativa opacidade e a grande complexidade da sociedade iraniana contribuam para torná-lo um enigma, essa imagem pode não corresponder à verdade. Fato é que ela foi construída e é sistematicamente reforçada por atores interessados em evitar o reposicionamento iraniano no tabuleiro geopolítico regional, como os países árabes do Golfo Pérsico, Israel e os Estados Unidos.

Também é fato que, nesses três anos, não apenas se impôs uma situação de intenso sofrimento à população iraniana, desnecessariamente, como também se adiou o início do processo de reinserção plena do 
Irã na comunidade internacional, acaso criando condições para se evitar evoluções como a que se observou na Síria.

Mas o tempo transcorrido não volta. Hoje estamos diante de outra oportunidade, o Plano de Ação de Genebra, cuja implementação está em curso: em uma nova rodada de Iran Talks em Genebra, um acordo técnico estabeleceu o início do período de implementação do Plano de Ação, no dia 20 de janeiro. A partir dessa data, espera-se que o Irã dê início às medidas previstas no acordo de Genebra, como a diluição de metade de seu estoque de urânio enriquecido a $20 \%$ e a interrupção do enriquecimento acima desse montante.

No dia $1^{\underline{o}}$ de fevereiro, data em que Teerã comemora o aniversário da Revolução Iraniana, seu governo recebeu a primeira parcela de ativos descongelados como resultado do relaxamento de sanções previsto no acordo (BHADRAKUMAR, 2014). No dia 18 de fevereiro, os negociadores reunir-se-ão novamente para dar início à negociação de um acordo amplo de longo prazo, que deverá ser tecnicamente significativo e politicamente aceitável, tanto nos Estados Unidos quanto no Irã.

A comunidade internacional torce para que Genebra dê certo. Isso dependerá de que o Irã convença o Grupo de Viena de que não tenciona construir a bomba. Sua posição específica no imaginário da comunidade internacional e sua relevância para o equilíbrio de poder do Oriente Médio recomendam também boa vontade ao Ocidente pelo menos para questionar suas convicções com respeito ao Irã.

\section{Notas}

1. Grupo negociador composto pelos cinco membros permanentes do Conselho de Segurança da ONU, os P-5 (Estados Unidos, Reino Unido, França, China e Rússia), e pela Alemanha. 


\section{Antonio Jorge Ramalho da Rocha e Pérola}

Mourão de Souza Sardo de Abreu Pereira

2. Na percepção iraniana, interferências americanas mais profundas em seus assuntos internos remontam ao início dos anos 1950, na reação, em parceria com o Reino Unido, à nacionalização da indústria do petróleo (em 1951), e mais particularmente por ocasião do golpe de 1953, que retirou Mossadegh do poder.

3. Para outros depoimentos relevantes do presidente iraniano, ver o discurso na $68^{\underline{a}}$ Reunião da Assembleia Geral da ONU, em 24 de setembro de 2013, quando ele afirmou que "Sanções injustas, enquanto manifestação de violência estrutural, são intrinsecamente desumanas e contrárias à paz". Disponível em: $<$ http://gadebate.un.org/mwg-internal/de5fs23hu73ds/progress?id $=$ UAOt8jlxY8>. Acesso em: 5 fev. 2014. Ver também seu discurso no Fórum Mundial de Davos, em que sublinhou o uso de "política externa ativa para alcançar o desenvolvimento econômico". Disponível em: <http://iranprimer.usip. org/blog/2014/jan/23/rouhani-davos-invites-oil-execs-speech-tweets $>$. Acesso em: 3 fev. 2014.

4. A Agência mantém uma página de acompanhamento da situação nuclear do Irã: <http://www.iaea.org/newscenter/focus/iaeairan/index.shtml>.

5. A Associação para o Controle de Armas Nucleares estima que Israel possua entre 75 e 200 ogivas (ver: <http://www.armscontrol.org/factsheets/Nuclearweaponswhohaswhat >. Acesso em: 5 fev. 2014), enquanto o Painel Internacional sobre Material Físsil estimava que o país detinha, em julho de 2013, 0,3 tonelada de urânio altamente enriquecido e 0,84 tonelada de plutônio para uso não civil (ver: <http://fissilematerials.org/>. Acesso em: 5 fev. 2014).

6. Expressão cunhada pelo rei Abdallah da Jordânia em 2004, na sequência da vitória do partido xiita nas eleições do Iraque, que previu o crescimento da influência xiita a partir do Irã espraiando-se por todo o Oriente Médio.

7. Íntegra da Declaração de Teerã: <http://www.itamaraty.gov.br/sala-de-imprensa/notas-a-imprensa/declaracao-conjunta-de-ira-turquia-e-brasil-17de-maio-de-2010>.

8. Íntegra do Plano de Ação Conjunto de Genebra: <http://eeas.europa.eu/statements/docs/2013/131124_03_en.pdf>.

9. Grupo negociador composto por Estados Unidos, Rússia e França.

10. Urânio enriquecido entre $1 \%$ e $20 \%$. O urânio fracamente enriquecido ou LEU (do inglês, low-enriched uranium) é tipicamente utilizado a taxas de enriquecimento de $3 \%$ a $5 \%$ em reatores a água leve, o tipo mais usado no mundo. Reatores de pesquisa requerem taxas de enriquecimento de $12 \%$ a $20 \%-$ sendo que esta última concentração pode, dentro do limite regulamentar, ser uti- 
lizada como produto de substituição em reatores inicialmente concebidos para funcionar com urânio altamente enriquecido.

11. A íntegra traduzida da carta de Obama a Lula foi publicada pela Folha de S. Paulo: <http://www1.folha.uol.com.br/mundo/741132-leia-integra-traduzida-da-carta-de-barack-obama-a-lula-sobre-acordo-com-o-ira.shtml >.

12. Uma semana depois da assinatura da Declaração, o Irã enviou carta à AIEA confirmando os termos do documento, como previsto (AMORIM, 2011, p. 302).

13. Não houve, de fato, reciprocidade: "a reação formal dos países diretamente envolvidos na troca (Estados Unidos, França e Rússia) foi entregue ao diretor-geral da Agência Atômica em Viena no dia 9 de junho, apenas algumas horas antes da adoção, em Nova York, da Resolução 1929 (2010) do Conselho de Segurança" (AMORIM, 2011, p. 302).

14. A aprovação não foi unânime, o que, para Parsi (2012), enfraqueceu o recado que os EUA queriam transmitir ao Irã. Brasil e Turquia votaram contra e o Líbano absteve-se.

15. Cabe sublinhar um fato curioso em relação ao atual limite de enriquecimento de urânio a que se sujeita o Irã (5\%): hoje recebido como uma conquista do Plano de Ação Conjunto, há três anos esse limite foi considerado um problema. Além da mudança retórica do Grupo de Viena com respeito a essa questão, registre-se a contradição lógica entre essa posição e a de não reconhecer o direito iraniano a enriquecer urânio no marco do TNP.

16. A esse respeito, o ex-chanceler Celso Amorim (2011, p. 283, nota 2) constata que "a expressão 'comunidade internacional' costuma ser empregada como coletivo para um pequeno grupo de países ocidentais, membros permanentes do Conselho de Segurança. Quando os Estados Unidos, a França, o Reino Unido adotam um aposição comum, esta fica sendo a vontade da 'comunidade internacional"”.

\section{Referências Bibliográficas}

AMORIM, C. Conversas com jovens diplomatas. São Paulo: Benvirá, 2011. 
BARZEGAR, K. Iran and the Shiite Crescent: Myths and Realities. Brown Journal of World Affairs, v. 15, n. 1, p. 87-99, 2008.

BHADRAKUMAR, M. K. Defining Moment Approaching in Iran Talks. Indian Punchline: Reflections on Foreign Affairs. 2 Feb. 2014. Disponível em: $<$ http://blogs.rediff.com/mkbhadrakumar/2014/02/02/defining-moment-aproaching-in-iran-talks/>. Acesso em: 5 fev. 2014.

COHEN, R. Iran: After the Sanctions, what Next? Event Transcript. Carnegie Endowment for International Peace. 4 Oct. 2010. Disponível em: <http://carnegieendowment.org/files/iran_after_the_sanctions,_what_ next_04-10-2010_transcript\%5B1\%5D.pdf>. Acesso em: 6 fev. 2014.

DOMBEY, D. US Senator Opens Iran Nuclear Debate. Financial Times, 10 Jun. 2009. Disponível em: <http://www.ft.com/intl/cms/s/0/d5c6395e55e6-11de-ab7e-00144feabdc0.html?siteedition=intl\#axzz2sMBYUTyD $>$. Acesso em: 6 fev. 2014.

DUARTE, J. Sanções vão polarizar os hemisférios. Jornal do Brasil, 29 mai. 2010. Disponível em: <http://www.jb.com.br/internacional/noticias/2010/ 05/29/sancoes-vao-polarizar-hemisferios-diz-o-nobel-mohamed-elbaradei/>. Acesso em: 6 fev. 2014.

HAGEL, C. Speech as Delivered by Secretary of Defense Chuck Hagel. Munich Security Conference. Munique, 1ํㅡㄹ. Feb. 2014. Disponível em: $<\mathrm{http}: / /$ www.defense.gov/Speeches/Speech.aspx?SpeechID=1828>. Acesso em: 5 fev. 2014.

KERRY, J. Press Availability After P5+1 Talks. U. S. Department of State. 24 Nov. 2013. Disponível em: <http://www.state.gov/secretary/remarks/ 2013/11/218023.htm>. Acesso em: 6 fev. 2014.

PARSI, T. A Single Role of the Dice: Obama's Diplomacy. Yale: Yale University Press, 2012.

ROUHANI, H. What Iran Wants in 2014. Project Syndicate. 8 Jan. 2014. Disponível em: <http://www.project-syndicate.org/commentary/hassan-rouhanion-iran-s-new-moderationKWyda0A2ky8LxfUp.99>. Acesso em: 5 fev. 2014.

SLAUGHTER, A-M. Diplomacy is the Least Damaging Option with Iran. Financial Times, 9 Nov. 2011. Disponível em <http://blogs.ft.com/the-a-list/ 
Iran Talks: Das Palavras aos Atos. A

Declaração de Teerã e o Plano de Ação...

2011/11/09/diplomacy-is-the-least-damaging-option-with-iran/\# ixzz2sVDlPiDy>. Acesso em: 6 fev. 2014.

\section{Resumo}

\section{Iran Talks: Das Palavras aos Atos. A Declaração de Teerã e o Plano de Ação Conjunto de Genebra em Perspectiva}

Este artigo analisa a Declaração de Teerã, de 2010, e o Plano de Ação Conjunto de Genebra, de 2013. Ao examinar as razões que explicam por que esses dois processos negociadores sobre o programa nuclear iraniano alcançaram resultados e repercussão tão distintos, o artigo tece considerações de ordem identitária e geopolítica sobre o papel do Irã na comunidade internacional, em particular no Oriente Médio. Aspectos específicos de política interna do Irã e dos Estados Unidos também influenciaram os resultados dos acordos, razão pela qual integram a análise. O argumento central aqui exposto é o de que em 2010 as condições políticas no ambiente internacional e nos dois Estados inviabilizaram a Declaração de Teerã, que constituiu uma oportunidade perdida de iniciar o processo de plena reinserção do Irã na comunidade internacional.

Palavras-chave: Irã - Programa Nuclear Iraniano - Declaração de Teerã Plano de Ação Conjunto de Genebra

\section{Abstract}

\section{Iran Talks, from Words to Deeds. The Declaration of Tehran and the Geneva Joint Plan of Action in Perspective}

This article assesses and contrasts the core aspects of the 2010 Tehran Declaration and of the 2013 Geneva Joint Plan of Action. It argues that the political conditions at the international community, in Iran, and in the US, 


\section{Antonio Jorge Ramalho da Rocha e Pérola}

Mourão de Souza Sardo de Abreu Pereira

prevented the Teheran Declaration from succeeding. It was a missed opportunity to initiate the process of fully reinserting Iran in the international community. The article examines some reasons why these two negotiating processes about the Iranian nuclear program have reached different results and repercussion. It incorporates geopolitical and identitary considerations about Iran's role in the international community, particularly in the Middle East. Because they have influenced the evolution of events, selected aspects of both Iranian and American domestic politics are also part of the analysis.

Keywords: Iran - Iranian Nuclear Program - Declaration of Tehran Geneva Joint Plan of Action 